\title{
A Power Buffer in an Electric Driveline: Two Batteries Are Better Than One
}

\author{
Juan de Santiago, Florian Burmeister, Johan Lundin, and Janaina G. Oliveira \\ Division for Electricity, Uppsala University, Ångström, Laboratoriet, P.O. Box 534, 75121 Uppsala, Sweden \\ Correspondence should be addressed to Juan de Santiago; juan.santiago@angstrom.uu.se
}

Received 13 November 2013; Accepted 9 December 2013; Published 2 February 2014

Academic Editors: W. Li and H. H. Liu

Copyright (C) 2014 Juan de Santiago et al. This is an open access article distributed under the Creative Commons Attribution License, which permits unrestricted use, distribution, and reproduction in any medium, provided the original work is properly cited.

\begin{abstract}
Fuel cells and high energy density batteries have limited overrated capacity and slow power response. Ultracapacitors and flywheels are proposed to overcome these limitations and to facilitate regenerative braking in hybrid and electric vehicles. The simulations presented in this paper show that a Secondary Energy Storage Unit (SESU) enhances the performance of the drivelines as previously suggested and provides additional improvements. A combined design of the primary energy source and the SESU reduces the total weight and volume and increases the battery lifetime. A full-electric driveline is simulated using a standard EPA FTP-75 drive cycle. Then the same vehicle is simulated with as SESU and the results are compared. The same is done for a hybrid driveline. Two drivelines are used as references and then enhanced with an SESU; four simulations are presented in total. Simulation results show that an energy storage device with very low energy and high power allows better battery selection and energy management.
\end{abstract}

\section{Introduction}

Research in electric vehicles has a long history full of success and disappointment. There are great expectations that are fulfilled only recently with the latest developments in batteries. Batteries are the most challenging component of the electric car. Energy density is very low compared to gasoline. Electric cars have less range than gasoline as batteries become very heavy. Most commercial electric cars are intended for commuting purposes with an average range of less than $160 \mathrm{~km}$ [1]. The Tesla Model $S$ is the commercial electric car with higher range up to $480 \mathrm{~km}$ (300 miles) and the battery alone weighs $600 \mathrm{~kg}$ [2]. The battery is also an expensive component. Different forecasts agree that the price of future electric cars will be at least $\$ 5,000$ higher than conventional petrol cars even with scale economies [3].

The power and energy density is a compromise of the reagents density. There are batteries with high power density, but their energy density is limited. There are batteries with high energy density, but the power density is compromised. A Secondary Energy Storage Unit (SESU) has been proposed to improve the dynamic response of drivelines $[4,5]$. This paper argues that SESUs have a positive economic potential when the complete driveline is evaluated.
A power buffer is here defined as a component that can provide high power for short periods of time without compromising its lifetime. The power buffer would not be the main energy source but work in combination with Internal Combustion Engines (ICEs) or batteries. Practically, a power buffer could be ultracapacitors, flywheels, or high power density batteries.

The benefits of a power buffer in an electric/hybrid driveline are as follows:

(i) the battery power rating is lower and therefore cheaper and with higher energy density;

(ii) the power fluctuations in the battery are significantly reduced;

(iii) the dynamic response is enhanced.

The drawbacks of a power buffer are as follows:

(i) more components in the driveline;

(ii) it has its own associated losses.

The potential improvement are presented through the comparison of several simulations. Simulation models of an all-electric vehicle and a hybrid vehicle are compared with 
drivelines enhanced with an SESU. The simulations show that an SESU with a limited energy storage capacity reduces the battery power rating requirements dramatically.

\section{Background}

The energy storage of an SESU is made of ultracapacitors, flywheels, or high power density batteries. There have been previous successful experiences with these components in the transport sector. Here some projects are presented with focus on applications where the SESU acts as a power buffer.

2.1. Batteries. Batteries are devices that convert chemical energy into electricity and therefore they are limited by chemical thermodynamic and kinetic means. There are batteries with different chemical components and structures. Some have high power density and some have high energy density, but there are no batteries which can excel in both properties. The energy density increases with the thickness of the cathode and anode layers, but thick layers reduce the power density due to slow diffusion [6]. Most systems are designed with one type of batteries, but the combination of different batteries to achieve the best of both should be considered.

There are already examples of systems with combinations of different batteries. Digital cameras are equipped with a battery that delivers energy for some hundred shots (high power) and a second battery to keep the information like the date and settings for years (low power, long lifetime), so most of them are powered with rechargeable Li battery and a button battery. The same concept of two batteries is applicable also to electric vehicles. The most remarkable example of an SASU that acts as a power buffer developed for automation is the KERS system in Formula One. These batteries are rated $60 \mathrm{~kW}$ and $400 \mathrm{~kJ}$. They provide power for only 6.5 seconds per cycle and weigh only $60 \mathrm{~kg}$. The drawback is that the lifetime is limited to only one race that lasts 2 hours. The KERS system is designed to increase the performance and not to improve range or driveline economy as the SASU proposed in this paper.

2.2. Ultracapacitors. Ultracapacitors are similar to conventional capacitors although they are built with an electrolyte between layers instead of an inert solid dielectric resulting in a much higher capacity. Ultracapacitors have a high number of cycle's lifetime and high power density, although the cost is currently higher than competing technologies.

There are current projects in buses and trams. The strategy in these cases is to recharge very often, as often as at each bus stop so that the energy rating is very low. Projects with ultracapacitors in trams include a tram in Geneva by Stadler [7], a tram in Paris related to Alstom's STEEM project [8], the MITRAC project tested in Mannheim by Bombardier [9], and the trams equipped with CAF's onboard ACR ultracapacitor energy storage system for catenary-free operation in Zaragoza [10]. There are also buses powered with ultracapacitors like Shanghai Aowei developed by Sinautec in as early as 2006 [11] and the two buses operated in Umeå [12].
2.3. Flywheels. A flywheel is an energy storage device base on kinetic energy. The energy stored in a rotating disk is proportional to its moment of inertia and to the square of the rotational speed. There are flywheels with pure mechanical transmission and flywheels with a motor/generator that provide electric power, both have been applied to hybrid vehicles. An example of flywheels with mechanical transmission is the KERS system developed by Flybrid Systems developed for Formula One. It has been tested in different vehicles like the Mercedes Le Mans $24 \mathrm{~h}$ race [13] and by Volvo [14] as presented in Figure 1.

The flywheel may be driven by an electric motor/ generator creating an electromechanical battery. This type of energy storage is more suitable for hybrid and electric vehicles that are equipped with electric traction. Williams Hybrid Power has developed a technology used by Audi and Porsche among others [15] presented in Figure 2.

There are a number of projects that use flywheels beside motor sport applications. An early example is the CCM Energy Storage System developed by Siemens in the Netherlands [16]. Magnet Motor $\mathrm{GmbH}$ developed and tested 12 hybrid buses as presented in Figure 3. They prove survivability against accelerations over $6 \mathrm{~g}$ and one million cycles each [17]. There are also projects to develop flywheel base drivelines in heavier vehicles like the Alstom's Citadis tram powered by Williams Hybrid Power [18].

\section{Power Buffer Technologies}

As mentioned previously, the combination of a primary energy source, for example, batteries, and a power buffer can be used to meet the peak power requirements of an electric vehicle. Electric vehicle traction systems that combine an ultracapacitor or flywheel with the battery, also called dual power sources, have been evaluated before [19].

A simple idealized power management scheme can be implemented in the model such that

(i) the buffer unit normally supplies or absorbs the peak power;

(ii) the battery supplies the average power.

The speed and power demand simulated at wheel shafts of an ordinary vehicle during a standard FTP-75 (Federal Test Procedure) urban drive cycle are shown in Figures 4 and 5 . The vehicle considered for this simulation has a mass of $1350 \mathrm{~kg}$, a drag coefficient $\mathrm{Cx}$ of $0.7 \mathrm{~m}^{2}$, and a rolling resistance coefficient Crr of 0.01 . The power demand varies from $31 \mathrm{~kW}$ (when accelerating) to $-24 \mathrm{~kW}$ (when braking). However, the average electric power from the energy storage, needed to propel an ordinary vehicle according to a standard FTP-75 urban drive cycle, is about $4.4 \mathrm{~kW}$, that is, less than $15 \%$ of the maximum power required during the drive cycle. A power buffer could handle fluctuations in power to/from the wheels instead of transferring them to the battery.

The battery-ultracapacitor combination for vehicular applications has been reported in the literature [20-23]. Results claim that ultracapacitors offer high efficiency (around 90\%) and can be charged and discharged a large 


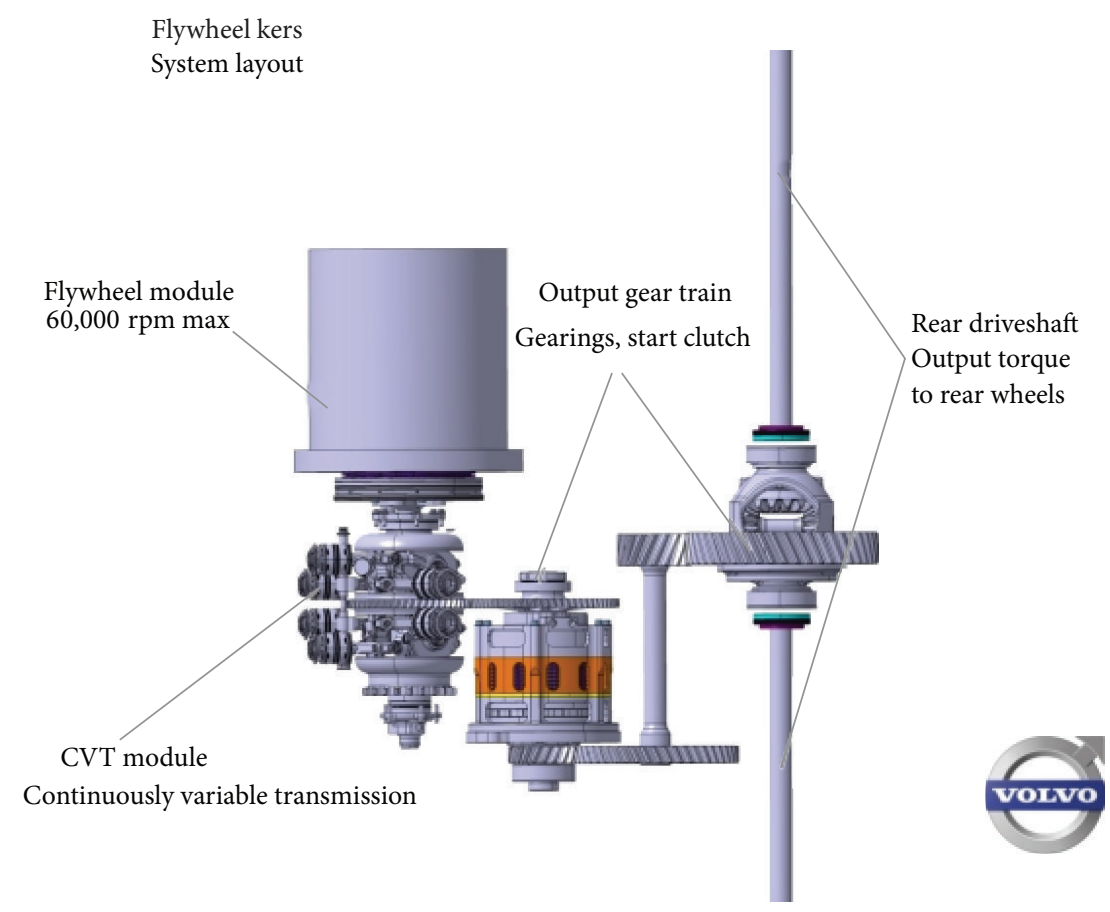

FIGURE 1: Schematic representation of a mechanical driven Flywheel.

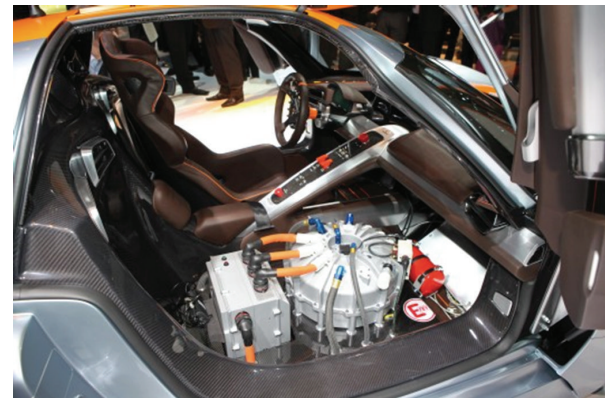

FIgUre 2: Flywheel in a hybrid Porsche 918 Spyder.

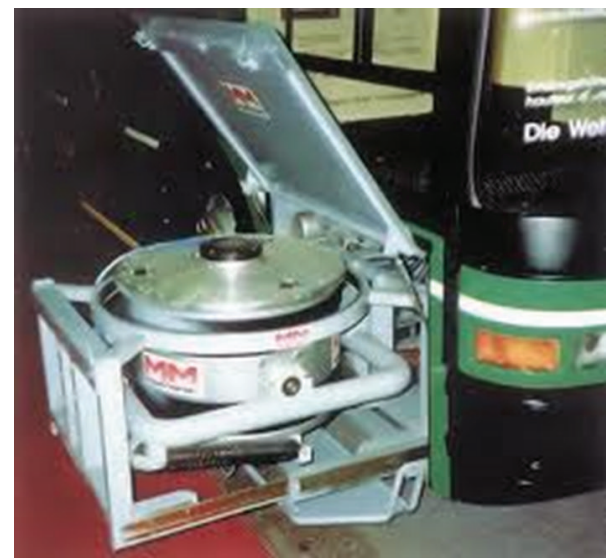

Figure 3: Magnet motor flywheel operated in trolleybuses in Basel, Switzerland.

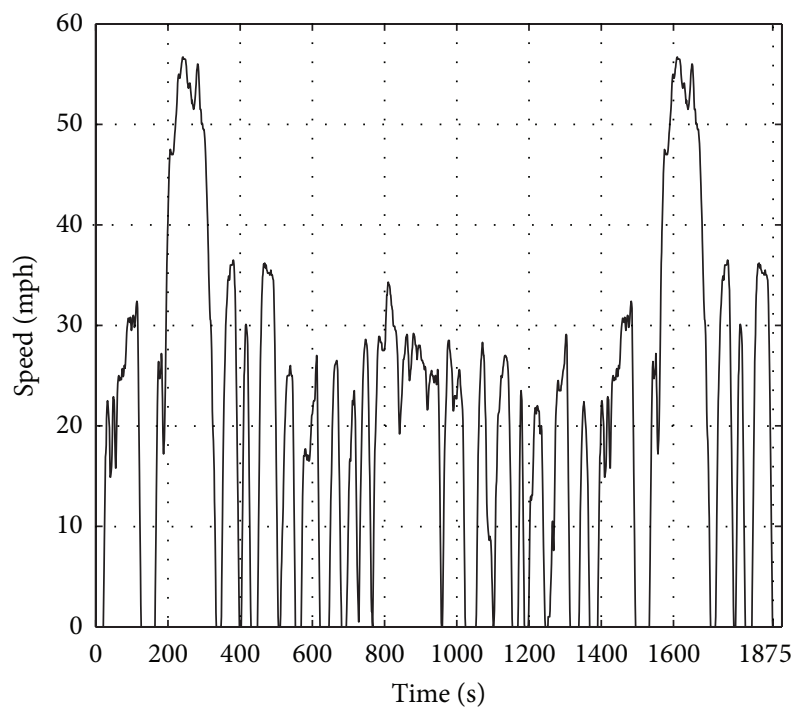

FIGURE 4: Speed profile in the EPA FTP-75 standard drive cycle.

number of times without performance deterioration. The drawback of ultracapacitor is its high cost, between 10 and $20 \$ / \mathrm{Wh}$. Flywheels, on the other hand, have an estimated $\mathrm{kWh}$ cost of 0.5 to $1 \$ / \mathrm{Wh}[24,25]$. Furthermore, flywheels offer steady voltage and power level, independent of load, temperature, or state of charge; no chemistry is included, thus no environmental pollution associated. The efficiency and life cycles are similar to the ones presented for ultracapacitors $[26,27]$. 


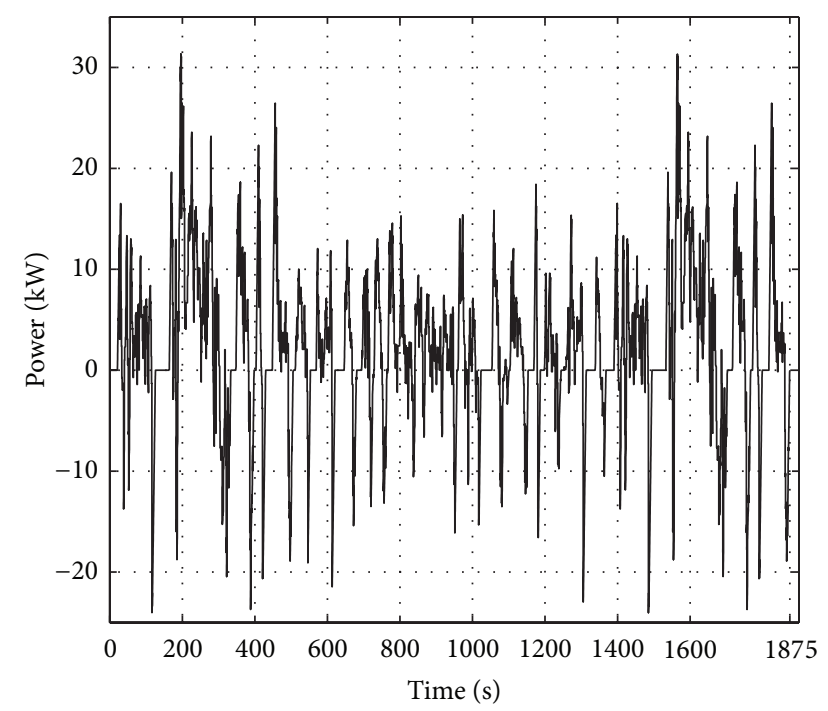

Figure 5: Power required to complete the EPA FTP-75 standard drive cycle.

Three operational modes according to the power flow have been identified [28]. In the normal mode operation the battery gives power to the wheels at the same time that recharges the SESU. At accelerating or uphill climbing, both the battery and the SESU deliver power to the wheels. At decelerating and downhill the main power flow goes exclusively to the SESU. The battery and the SESU are connected to the DC-link.

\section{Simulation Models}

Simulation of vehicle dynamics is a standard procedure [29]. Four different drivelines have been simulated using the standard drive cycle EPA FTP-75. The different drivelines have been classified in the following cases: Case Ia, full-electric driveline; Case Ib, full-electric driveline with a SESU; Case IIa, hybrid driveline; Case IIb, hybrid driveline with a SESU.

Case Ia refers to a full electric driveline. The driveline has one power source considered ideal; that is, it can deliver as much power as required and is charged with enough energy to complete the drive cycle. Case Ib is simulated with power and energy restrictions. The battery is charged with enough energy to complete the cycle but has a power rating that cannot be exceeded. A control that prevents fast changes in power is also implemented. Power transients are limited to increase battery lifetime. The SESU-now added to the systemis a power buffer, therefore it delivers all power required but it has a limited energy capacity. In the event that battery delivers power and the requirement from the drive cycle suddenly drops, then the battery will slowly reduce the power delivery and the energy difference will be stored in the SESU. In the event that the SESU is discharged and the power requirement exceeds the battery power rating, then the driveline cannot deliver the required performance. The discrepancy between power demand and delivery will be calculated and discussed.
Simulations show the power flow without considering time delays in the motor dynamics so the conclusions are applicable to both Internal Combustion Engine (ICE) drivelines and full electric drivelines with one battery pack. For simplicity the full electric driveline has been selected in this simulation.

Case IIa refers to a driveline with two different power sources, this is, a hybrid driveline with an ICE and a battery pack. Again, the simulations show the power flow in a generic hybrid driveline without discussing the configuration.

Case IIb refers to the driveline presented in Case IIa with an additional power buffer. This scenario discusses the case where a power buffer can reduce the cost of the battery and increase its lifetime by reducing its power demand.

The drivelines are modelled with three different components: power buffer, battery, and IC engine. Here the characteristics of the components in each case are presented.

4.1. Power Buffer. We argue that the driveline capability would be enhanced with an element capable to deliver instant power even with a low energy rating. The power buffer could be a capacitor, an ultracapacitor, a flywheel, or a battery with high power rating. The characteristic that has to be highlighted in the simulation is the high power capability without degradation. The SESU is therefore simulated as a power source with limited rated energy storage and unrestricted power capability.

4.2. Batteries. Batteries in the base cases have been modelled differently than batteries working in parallel with a power buffer. The batteries on the reference drivelines (Cases Ia and IIa) have to provide the power to fulfil the drive cycle and therefore their power rating is the maximum power demand. They are modelled as ideal batteries without any dynamic restriction in the power transients. On the contrary, batteries in the drivelines with power buffers (Case Ib and IIb) are simulated as power sources with a slow PI control so that the power transients are limited. The increase in life time with lower $d P / d t$ is uncertain and quantitative parameters are not available, so the results presented are qualitative.

4.3. Internal Combustion Engine (ICE). The main advantage of hybrid drivelines is that the IC motor operates close to its highest efficiency point. ICEs have a regulation capability at the price of lower efficiency. In this study the IC engine is operated strictly at its highest efficiency point without any regulation, just an on/off control at its power rating. This extreme case illustrates the philosophy of hybridization.

\section{Simulation Results}

Four different drivelines have been simulated using the standard EPA FTP-75 drive cycles. The power requirement to complete the cycle has been calculated for a standard vehicle considering the same internal friction and losses regardless of the driveline as the driveline optimization is out of the scope of this study. 




FIGURE 6: Schematic representation of Case Ia: driveline with one power source.

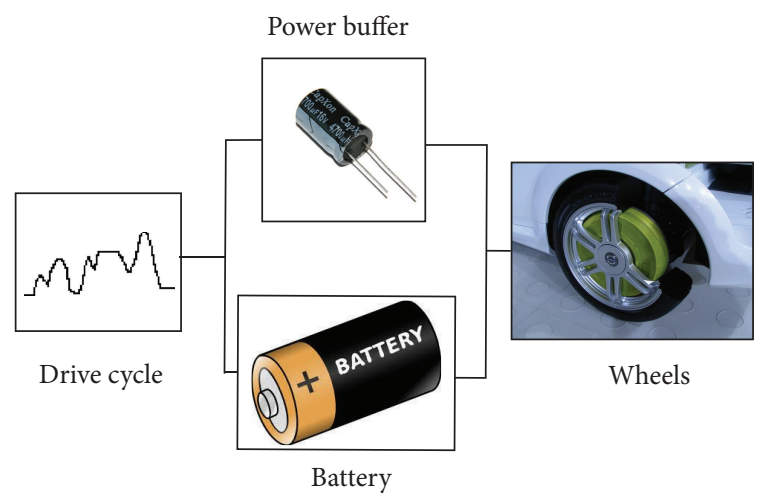

FIGURE 7: Schematic representation of Case Ib driveline with one power source with limited power and $d P / d t$ and a power buffer.

5.1. Model Reference Case Ia. Case Ia simulates a full electric vehicle driveline presented in Figure 6. The battery rating is selected over the maximum power demand in the drive cycle so that the vehicle can follow the power requirements presented in Figure 5.

5.2. Case Ib. The conventional all electric driveline is enhanced with a power buffer in Case Ib. The battery in this new case is simulated with limited power and $d P / d t$. The power buffer is simulated with infinite power capability but limited energy rating. The driveline components are represented in Figure 7.

The Case Ib driveline configuration is simulated sweeping two parameters: the battery power limit and the power buffer energy capacity. The initial conditions are set so that the power buffer is charged up to $50 \%$ of its nominal energy rating and the battery power reaches $1.5 \mathrm{~kW}$ (or rated power when this is lower than $1.5 \mathrm{~kW}$ ).

The driveline has been simulated with different maximum power limits in the battery and energy rating in the power buffer. The results of the simulations are shown in Figure 8. The power demand cannot be reached for some combinations of low rated battery and power buffers. The driver will notice that the car cannot accelerate fast enough for some battery and SESU combinations. The difference between the power demand and the power delivered measured in the simulation is integrated and referred to as "energy mismatch." The energy mismatch is the figure of merit of the drivelines performance.

The solution is not linear; higher power in the battery may result in higher deviation from the power demand. This phenomenon is due to the $d P / d t$ limit in the battery. Batteries

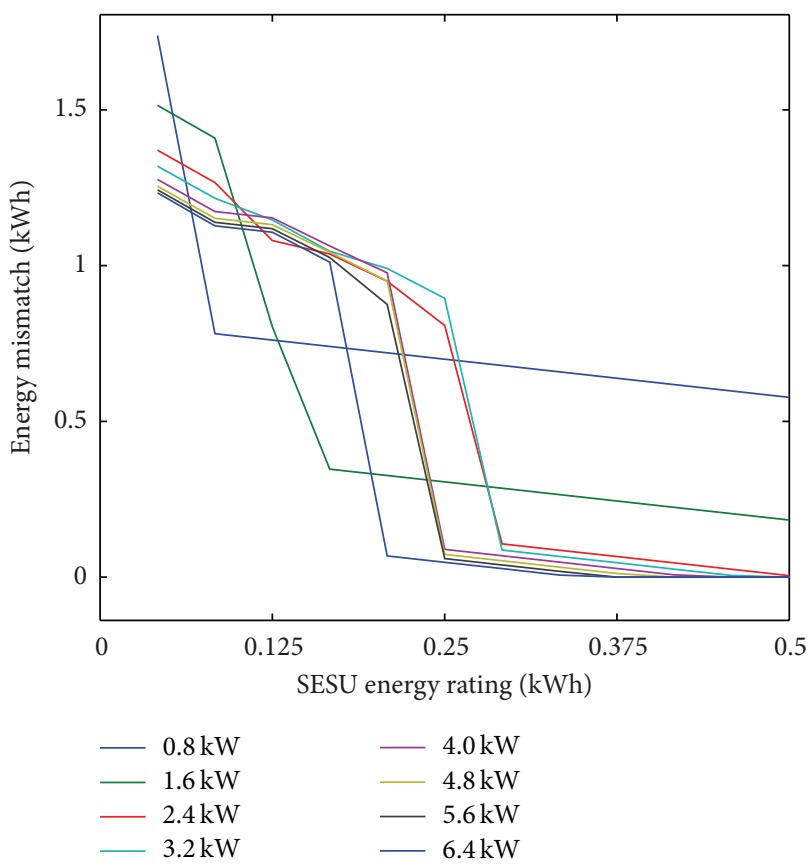

FIGURE 8: Result of the simulation of the EPA FTP-75 drive cycle for various combinations of batteries and power buffers. Batteries are limited in power while power buffers are limited in energy storage capacity. The lines show the deviation from the desired drive cycle.

with high power take long time to rise and reduce power delivery. Regenerative braking is represented as a negative power flow. Energy cannot be recovered when the power buffer is saturated. The energy lost during regenerative braking is added as negative and it is perceived as a positive effect in the total energy mismatch.

The system performed reasonably well for power buffers over $0.25 \mathrm{kWh}$ and battery limited to $4.8 \mathrm{~kW}$, for the restrictions and power flow considered in the simulations.

The power delivered to the wheels with a battery rated with $4.8 \mathrm{~kW}$ and a power buffer limited to $0.25 \mathrm{kWh}$ is presented in Figure 9 . The power delivered by the battery is much smoother than in the power profile presented in Figure 5.

The improvement with a power buffer is the reduction of the power rating in the battery from 30 to $4.8 \mathrm{~kW}$ at a cost of an extra power buffer rated $0.25 \mathrm{kWh}$.

5.3. Case IIa: Model Reference Hybrid. The hybrid reference driveline consists of an ICE and a battery as presented in Figure 10. The advantage in hybrid driveline is that the ICE works at its highest efficiency points. The paradigm is operating the ICE constantly at its highest efficiency point. This simulation presents the ICE as an on/off power source while the battery delivers the power difference. The battery delivers power when the driver requires more than the ICE rating and absorbs energy when the power demand is lower than the motor rating. The IC motor starts when the battery is empty and stops when the battery is full. 


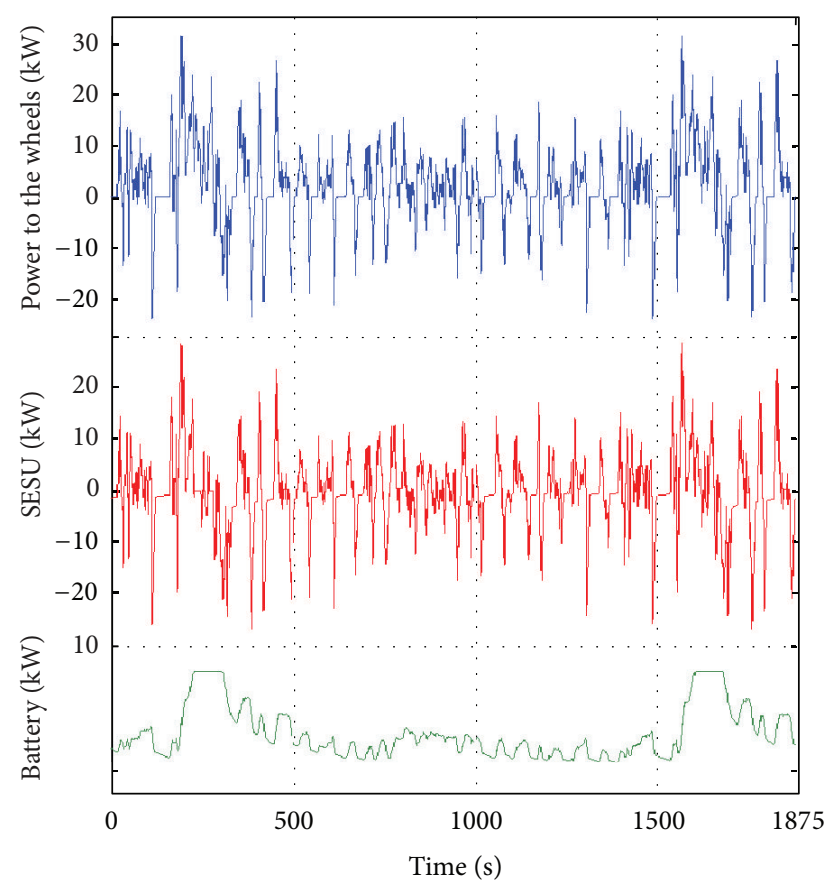

Figure 9: Power delivered to the wheels (blue) by the battery (green) and the power buffer (red) during the EPA FTP-75 standard drive cycle. The battery is rated $4.8 \mathrm{~kW}$ and a power buffer limited to $0.25 \mathrm{kWh}$. The battery and the power buffer are capable to follow the power demand, so the power mismatch is zero. The integral of this mismatch is the energy mismatch presented in Figure 8.

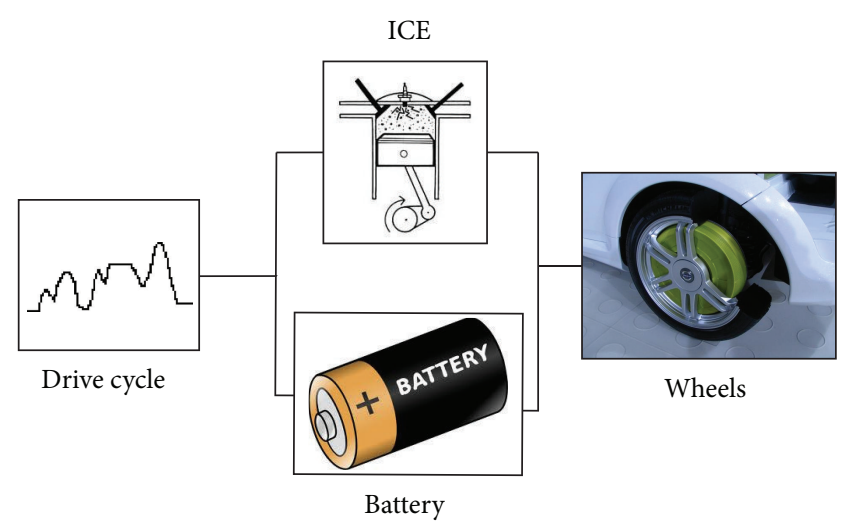

FIGURE 10: Schematic representation of Case IIa: hybrid reference driveline. The power is delivered by an IC motor and a battery working in parallel.

TABLE 1: Battery and ICE parameters in Case IIa driveline.

\begin{tabular}{lc}
\hline & Rating \\
\hline ICE & $10 \mathrm{~kW}$ \\
Battery & $0.5 \mathrm{kWh}$ \\
\hline
\end{tabular}

A low energy battery would force continuous start and stop cycles to the ICE. In the contrary, a low power ICE would result in continuous operation. The ICE and the battery ratings selected for the reference driveline are selected so that

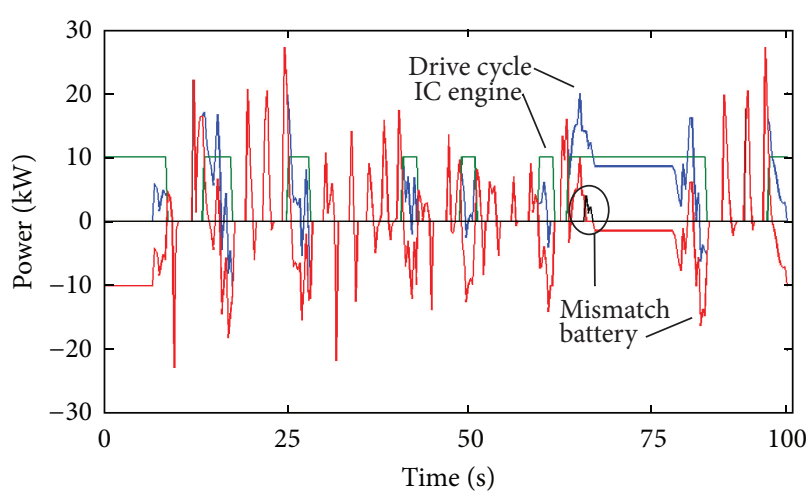

FIgURE 11: Power delivered to the wheels (blue) by the battery (red) and ICE (green) during the EPA FTP-75 standard drive cycle. The ICE has an on/off control while the battery is capable to follow the power demand up to the energy rating. The power mismatch is close but not zero (black). For clarity, only the first 100 seconds of the simulations are presented.

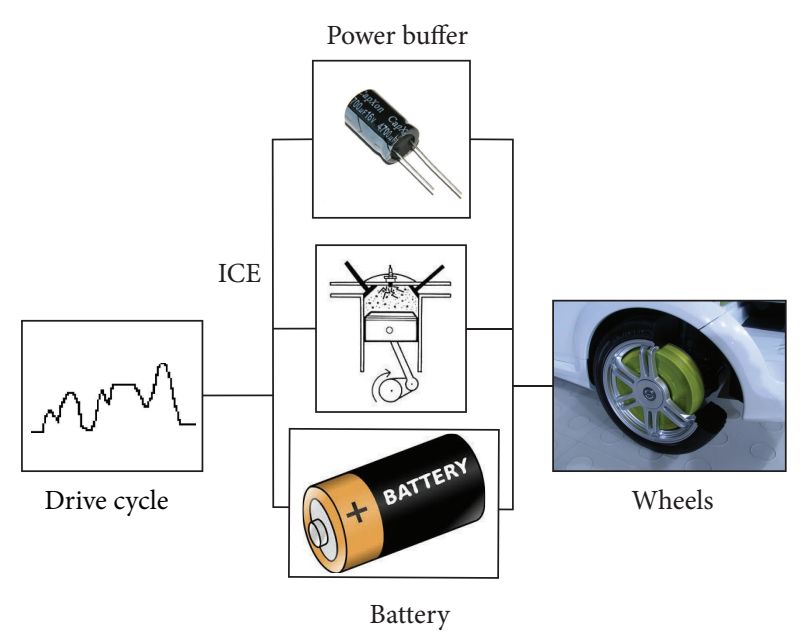

FIGURE 12: Schematic representation of Case IIb: hybrid driveline with a power buffer.

several start and stop of the ICE during the drive cycle can show the functionality of hybrid drivelines. The values are presented in Table 1.

The EPA FTP-75 drive cycle is simulated and results are presented in Figure 11. At one point the power demand is higher than the ICE rating and the battery is discharged. A power mismatch occurs under these circumstances.

5.4. Case IIb: Hybrid Driveline with a Power Buffer. Case IIb driveline configuration comprises a hybrid driveline (ICE and battery) enhanced with a SESU. The battery control is implemented with a restrictive PI to prevent fast power transients. The mismatch between the power required and the power delivered by the on/off ICE and the slow response battery is delivered by the power buffer. The driveline schematics are presented in Figure 12.

There are many degrees of freedom in ICE, battery, and SESU power and energy ratings that some restrictions have 
TABLE 2: Battery and ICE parameters in Case IIb driveline.

\begin{tabular}{lc}
\hline & Rating \\
\hline ICE & $10 \mathrm{~kW}$ \\
Battery + power buffer & $0.5 \mathrm{kWh}$ \\
Battery initial SoC & $50 \%$ \\
Power buffer SoC & $50 \%$ \\
\hline
\end{tabular}

TABle 3: Properties of the batteries considered.

\begin{tabular}{lcc}
\hline Li Battery model & Wh/kg & W/kg \\
\hline Saft (a) & 77 & 1,550 \\
Saft (b) & 140 & 476 \\
\hline
\end{tabular}

TABLE 4: Ultracapacitor characteristics considered.

\begin{tabular}{lccc}
\hline Model & Wh $/ \mathrm{kg}$ & $\mathrm{W} / \mathrm{kg}$ & $\$ / \mathrm{kWh}$ \\
\hline BCAP3000 P270 K0X & 6.0 & 5,900 & 30,000 \\
\hline
\end{tabular}

been introduced to simplify the presentation of results. The energy stored in the battery and the power buffer is set as constant. $0.5 \mathrm{kWh}$ is the compromised value selected. For example, if the battery is modelled with $0.4 \mathrm{kWh}$ then the power buffer would be modelled with $0.1 \mathrm{kWh}$. The power in the ICE is set to $10 \mathrm{~kW}$ and the state of charge (SoC) is $50 \%$ at the beginning of the drive cycle. The main parameters of the simulation are summarized in Table 2 .

The driveline is simulated for different battery power ratings. The driveline is not always able to deliver the power demanded in the drive cycle under all the parameter combinations. Figure 13 shows the energy mismatch between the power demanded for the drive cycle and the power delivered by the ICE, battery, and power buffer together. The mismatch occurs when the SESU is fully charged and it is unable to absorb regenerative braking. The mismatch in the simulation seen in Figure 14 occurs when the battery is increasing the charging rate but, because of the restriction in the power transient, it cannot absorb all the energy from the brake. Note that the energy mismatch is negative, instead of positive values as in Case I. The power flow for one of the parameter combinations is presented in Figure 14.

\section{Discussion}

The simulations show that the introduction of an SESU in the driveline reduces the power requirements and stress of the battery. The design of a driveline is a compromise of weight, range, life time of components, and cost. The optimization process starts with the performance requirements of the driveline. Then an objective function is defined. The minimum in the objective function gives the optimal solution. All parameters should be described as "cost" or some parameters used as a reference in the optimization. For example, if efficiency is the optimization function variable, then all other parameters are translated into efficiency with different weights. In [30] each $\mathrm{kg}$ of weight is interpreted as $5 \%$ of friction loss. The solution of the optimization gives the system

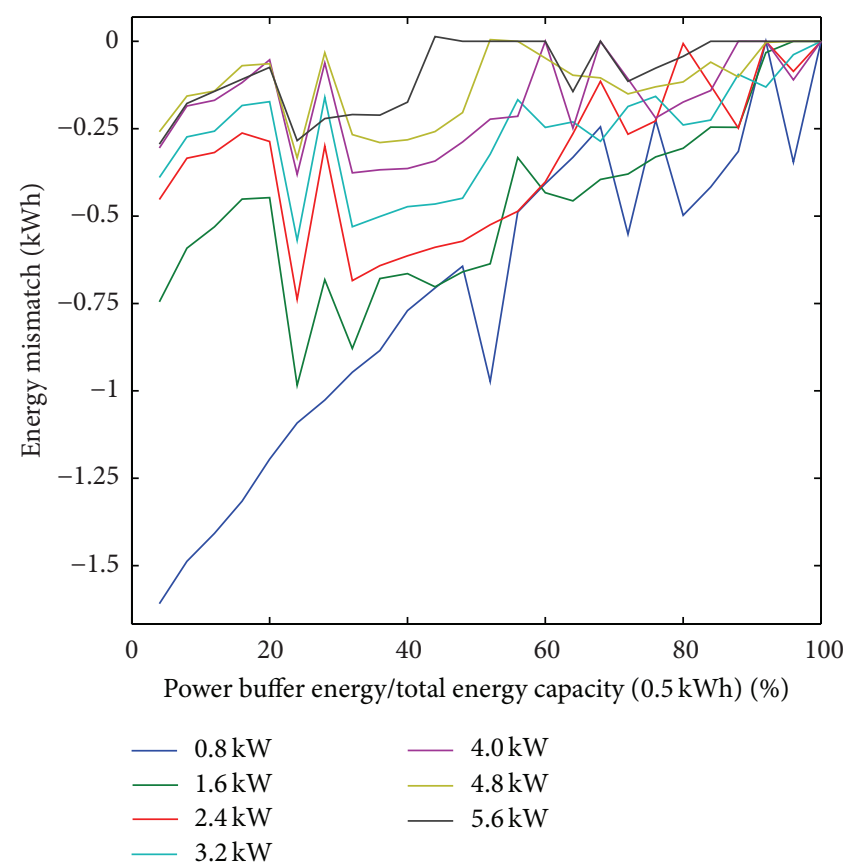

FIGURE 13: Energy mismatch between the power demanded for the drive cycle and the power delivered by the ICE, Battery and Power buffer together. Each line represents one battery power rating.



FIgURE 14: Power delivered to the wheels (black) by a $4 \mathrm{~kW}$ battery (green), power buffer (grey), and ICE (brown) during the EPA FTP75 standard drive cycle. The battery and the power buffer have the same $0.25 \mathrm{kWh}$ rating. The negative power mismatch (red) occurs when the SESU is fully loaded and is unable to store regenerative braking. 
TABLE 5: Battery pack and SESU cost and weight for three different driveline configurations.

\begin{tabular}{lccc}
\hline Components & $\mathrm{kWh}$ & $\mathrm{kg}$ & \multicolumn{1}{c}{$\$$} \\
\hline Base case battery-Type (a) & 15 & 195 & 17,800 \\
Low power density battery-Type (b) & 15 & 407 & 11,600 \\
SESU ultracapacitor & 0.25 & 23 & 7,500 \\
SESU battery & 1.7 & & 2,000 \\
Total energy storage & 15 & 195 & 147 \\
$\quad$ Base case - EV without SESU & 15.25 & 130 & 19,100 \\
$\quad$ Battery (b) + supercapacitor SESU & 16.7 & & 13,600 \\
$\quad$ Battery (b) + battery (a) SESU & & -48 & -60 \\
SESU compared with base case & +0.25 & -65 & $-4,200$ \\
$\quad$ Battery (b) + supercapacitor SESU & +1.7 & & \\
Battery (b) + battery (a) SESU & & & \\
\hline
\end{tabular}

losses minimum, which is different to each component minimum. The most efficient motor and batteries may not give the best system performance.

Here, a simple show case is presented as an example of the benefit of an SESU. Drivelines Ia and Ib are compared. A commercial ultracapacitor and a high power density battery are considered as the power buffer unit. The comparison is based on a $15 \mathrm{kWh}$ energy storage capacity in the battery, a reasonable energy storage in commercial electric vehicles [1]. The SESU is rated $0.25 \mathrm{kWh}$ and $35 \mathrm{~kW}$. Energy is the limiting factor for ultracapacitors and power for batteries. Table 3 presents the reference values of power and energy densities of commercial batteries considered in this showcase [1]. It is assumed that conventional drivelines use high power batteries (type (a)) and a driveline with an SESU would use high energy density (type (b)) or an ultracapacitor. High energy density batteries are more economical than high power density in terms of $\mathrm{kW} / \$$. The price for both types will be estimated (1) [31]. The ultracapacitor for transport applications properties and price are presented in Table 4 [32]. Consider the following:

$$
\text { Battery cost }=\$ 22 P+\$ 700 E+\$ 680 \text {. }
$$

Case Ia with a pure electric driveline is the base case. The battery cost and weight for $15 \mathrm{kWh}$ are presented in Table 5 . The base case is compared with two cases improved with an SESU, one based on ultracapacitors and one based on high power batteries. The base case has an energy storage rating of $15 \mathrm{kWh}$ from high power batteries. The cases with a SESU has an energy rating of $15 \mathrm{kWh}$ from low power density batteries plus the extra energy from the batteries.

An ultracapacitor for transport rated $0.25 \mathrm{kWh}$ contributes with an extra cost of $\$ 7,500$ and an extra weight of $40 \mathrm{~kg}$. An alternative SESU based on high power density batteries is evaluated. $35 \mathrm{~kW}$ of high power density batteries contributes with an extra cost of $\$ 2,000$ and an extra weight of $23 \mathrm{~kg}$.

The SESU reduces weight in the driveline up to one third and potentially reduces the system cost. The balance between energy storage capacity and SESU depends on the drive cycle and energy storage rating so new optimizations are required for each case.
Ultracapacitors seem uneconomical compared with batteries. Ultracapacitors have much longer lifetime than batteries for frequent charge-discharge cycles as in a SESU. It should be taken into consideration in the lifetime economy of the driveline. Flywheels are also a feasible option with similar performance to ultracapacitors.

\section{Conclusion}

All electric and hybrid drivelines benefit from an extra Secondary Energy Storage Unit (SESU) that balances power transients. The SESU could be an ultracapacitor, a flywheel or an extra small high power density battery. The SESU can potentially reduce the cost and weight of the energy storage, increase the battery lifetime and increase the dynamic performance. The drawback is an increase in complexity because the extra component in the system.

The simulations of a standard EPA FTP-75 drive cycle shows that a SESU requires an energy rating of $0.25 \mathrm{kWh}$ to smooth all power transients. The advantage for the battery is the reduction in power rating from 30 to $4.8 \mathrm{~kW}$ and the increase of lifetime due to better power flow management.

A case study is presented where a driveline with standard batteries is compared with drivelines enhanced with a SESU; one based on ultracapacitors and one based on high power density batteries. It is shown that the weight is significantly reduced for both case, while the price may be reduced depending on the components cost. Flywheels are also feasible for SESUs.

\section{Conflict of Interests}

The authors declare that there is no conflict of interests regarding the publication of this paper.

\section{Acknowledgments}

This work was conducted within the STandUp for ENERGY strategic research framework and supported by the Swedish Hybrid Vehicle Centre (SHC). 


\section{References}

[1] J. de Santiago, H. Bernhoff, B. Ekergård et al., "Electrical motor drivelines in commercial all-electric vehicles: a review," IEEE Transactions on Vehicular Technology, vol. 61, no. 2, pp. 475-484, 2012.

[2] http://www.caranddriver.com/reviews/2013-tesla-model-s-testreview, 2013.

[3] L. Cheah and J. Heywood, "The cost of vehicle electrification: a literature review," in Proceedings of the MIT Energy Initiative Symposium, Sloan Automotive Laboratory, Massachusetts Institute of Technology, Cambridge, Mass, USA, April 2010.

[4] B. Szabados and U. Schaible, "Peak power bi-directional transfer from high speed flywheel to electrical regulated bus voltage system: a practical proposal for vehicular technology," IEEE Transactions on Energy Conversion, vol. 13, no. 1, pp. 34-41, 1998.

[5] S. Mallika and R. Saravana Kumar, "Review on ultracapacitorbattery interface for energy management system," International Journal of Engineering and Technology, vol. 3, no. 1, pp. 37-43, 2011.

[6] M. Roberts, P. Johns, J. Owen et al., "3D lithium ion batteriesfrom fundamentals to fabrication," Journal of Materials Chemistry, vol. 21, no. 27, pp. 9876-9890, 2011.

[7] http://www.railwaygazette.com/news/single-view/view/genevetram-trial-assesses-supercapacitor-performance.htm, 2013.

[8] http://www.railwaygazette.com/news/single-view/view/supercapacitors-to-be-tested-on-paris-steem-tram.html, 2013.

[9] M. Steiner, M. Klohr, and S. Pagiela, "Energy storage system with Ultracaps on board of railway vehicles," in Proceedings of the European Conference on Power Electronics and Applications (EPE '07), September 2007.

[10] http://www.railwaygazette.com/news/single-view/view/zaragoza-tram-enters-service.html, 2013.

[11] http://www.treehugger.com/author/michael-graham-richard/ page/94/, 2013.

[12] http://www.nordicgreen.net/startups/article/swedish-townume-orders-two-full-size-electric-buses-hybricon-swedishstart?page $=1,2013$.

[13] http://www.flybridsystems.com/CFTKERS.html, 2013.

[14] http://reviews.cnet.com/8301-13746_7-20068342-48.html, 2013.

[15] http://www.gizmag.com/porsche-hybrid-918-spyder-770-hp/ 22551/, 2013.

[16] http://www.ccm.nl/en/projects/projects/22-energy-storage-system, 2013.

[17] F. N. Werfel, U. Floegel-Delor, T. Riedel et al., " $250 \mathrm{~kW}$ flywheel with HTS magnetic bearing for industrial use," Journal of Physics: Conference Series, vol. 97, no. 1, Article ID 012206, 2008.

[18] http://www.railwaygazette.com/news/industry-technology/single-view/view/alstom-to-test-onboard-flywheel-energy-storage.html, 2013.

[19] P. H. Mellor, N. Schofield, D. Howe, and Flywheel a, "nd supercapacitor peak power buffer technologies," in Proceedings of the IEE Seminar on Electric, Hybrid and Fuel Cell Vehicles, pp. 1-5, Durham, UK, 2000.

[20] S. Pay and Y. Baghzouz, "Effectiveness of battery-supercapacitor combination in electric vehicles," in Proceedings of the Power Tech Conference, pp. 1-6, Bologna, Italy, 2003.

[21] T. A. Smith, J. P. Mars, and G. A. Turner, "Using supercapacitors to improve battery performance," in Proceedings of the IEEE 33rd Annual Power Electronics Specialists Conference (PESC '02), pp. 124-128, June 2002.
[22] Y.-P. Yang, J.-J. Liu, and T.-H. Hu, "An energy management system for a directly-driven electric scooter," Energy Conversion and Management, vol. 52, no. 1, pp. 621-629, 2011.

[23] J. Dixon, M. Ortuzar, and E. Wiechmann, "Regenerative braking for an electric vehicle using ultracapacitors and a buck-boost converter," in Proceedings of 17th International Electric Vehicle Symposium, pp. 1-6, Montreal, Canada, 2000.

[24] I. Hadjipaschalis, A. Poullikkas, and V. Efthimiou, "Overview of current and future energy storage technologies for electric power applications," Renewable and Sustainable Energy Reviews, vol. 13, no. 6-7, pp. 1513-1522, 2009.

[25] G. Pistoia, Battery Operated Devices and Systems, Elsevier, 2008.

[26] J. Cibulka, "Kinetic energy recovery system by means of flywheel energy storage," Advanced Engineering, vol. 3, no. 1, pp. 27-38, 2009.

[27] A. Barin, L. N. Canha, A. Da Rosa Abaide, and K. F. Magnago, "Selection of storage energy technologies in a power quality scenario-the AHP and the fuzzy logic," in Proceedings of the 35th Annual Conference of the IEEE Industrial Electronics Society (IECON '09), pp. 3615-3620, November 2009.

[28] X. X. Fu and X. Xie, "The control strategy of flywheel battery for electric vehicles," in Proceedings of the IEEE International Conference on Control and Automation (ICCA '07), pp. 492-496, June 2007.

[29] P. Shakouri, A. Ordys, P. Darnell, and P. Kavanagh, "Fuel efficiency by coasting in the vehicle," International Journal of Vehicular Technology, vol. 2013, Article ID 391650, 14 pages, 2013.

[30] B. Mecrow, J. Bennett, A. Jack, D. Atkinson, and A. Freeman, "Very high efficiency drives for solar powered unmanned aircraft," in Proceedings of the International Conference on Electrical Machines (ICEM '08), September 2008.

[31] R. Shankar, J. Marco, and F. Assadian, “The novel application of optimization and charge blended energy management control for component downsizing within a plug-in hybrid electric vehicle," Energies, vol. 5, no. 12, pp. 4892-4923, 2012.

[32] “K2 SERIES 650 F-3, 000 F ULTRACAPACITORS,” Data Sheet, Maxwell Technologies, San Diego, Calif, USA. 

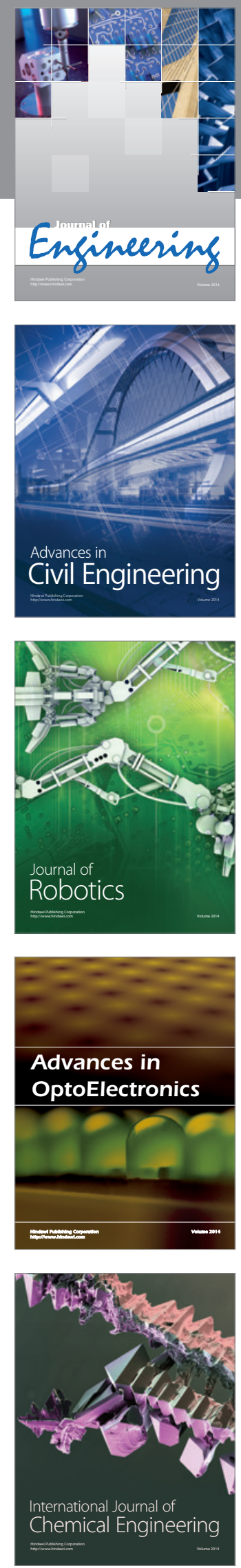

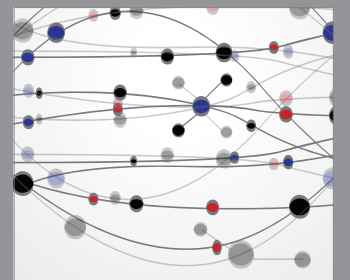

The Scientific World Journal
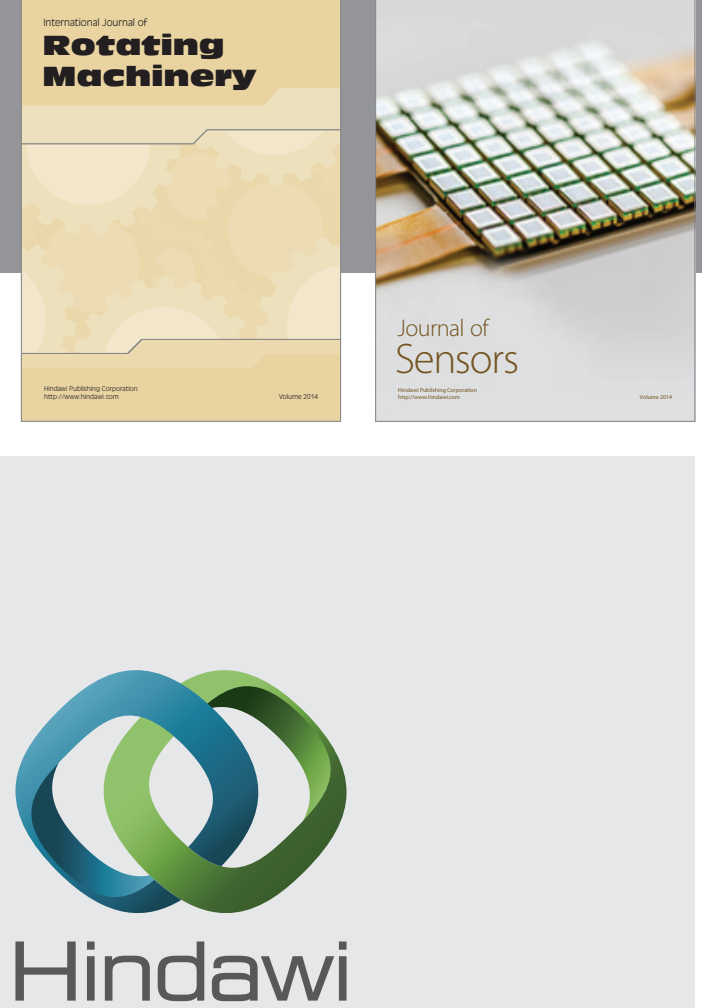

Submit your manuscripts at http://www.hindawi.com
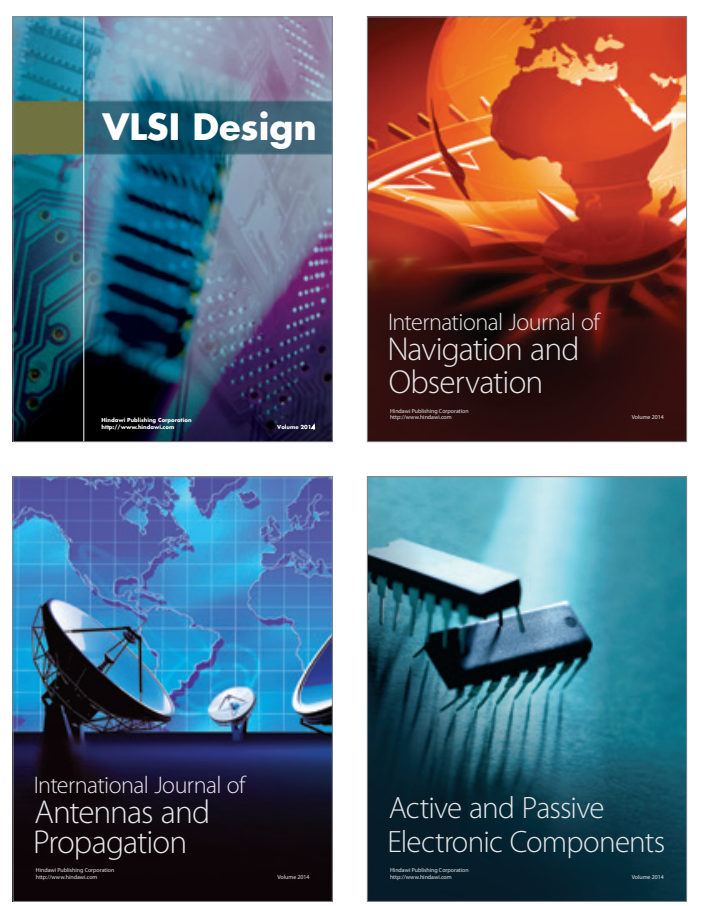


Journal of

Control Science

and Engineering
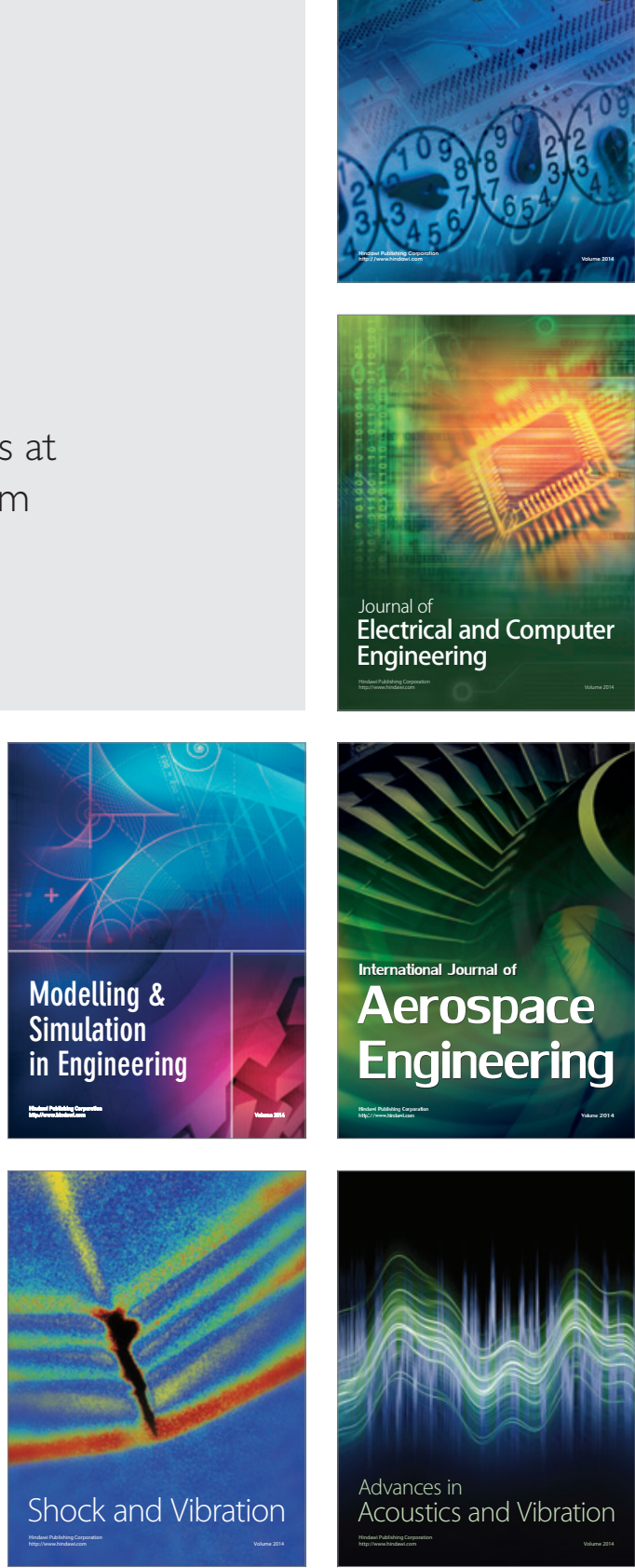